\title{
Fitotoxicidade de extratos etanólicos de frutos e folhas de Banisteriopsis oxyclada (A. Juss.) B. Gates sobre o crescimento de plantas daninhas
}

\author{
Simoni Anese $1 \%$ \\ Patricia Umeda Grisi ${ }^{2}$ \\ Maristela Imatomi ${ }^{2}$ \\ Viviane de Cassia Pereira ${ }^{2}$ \\ Sonia Cristina Juliano Gualtieri ${ }^{2}$

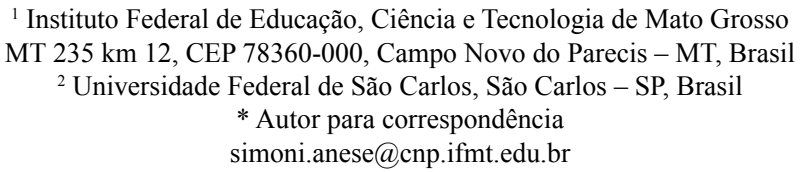

Submetido em 04/08/2015

Aceito para publicação em 19/12/2015

\section{Resumo}

O objetivo deste estudo foi avaliar o efeito do extrato etanólico de folhas e frutos de Banisteriopsis oxyclada sobre o crescimento de plântulas de amendoim-bravo e capim-arroz. O extrato bruto etanólico foi preparado na proporção de $100 \mathrm{~g}$ de material vegetal seco para $500 \mathrm{~mL}$ de etanol. A partir deste, os extratos foram solubilizados em solução tampão e dimetil sulfóxido (DMSO), nas concentrações 10,0; 7,5; 5,0 e 2,5 mg/mL. Foi avaliado o crescimento do sistema radicular, da parte aérea e das células do metaxilema radicular das plântulas. Os extratos etanólicos de folhas e frutos de $B$. oxyclada exerceram atividade inibitória no crescimento radicular de plântulas de capim-arroz e amendoim-bravo, com efeito dependente da concentração. Foi observada redução no crescimento da parte aérea apenas nas plântulas de amendoim-bravo. A redução no crescimento radicular das plântulas de amendoim-bravo pode estar relacionada à diminuição no alongamento das células do metaxilema. Banisteriopsis oxyclada apresenta propriedades fitotóxicas e pode ser considerada uma alternativa no controle das plantas daninhas estudadas, com base em produtos naturais.

Palavras-chave: Alelopatia; Echinochloa crus-galli; Euphorbia heterophylla; Inibição

\section{Abstract}

Phytotoxicity of ethanolic extracts of fruits and leaves of Banisteriopsis oxyclada (A. Juss.) B. Gates on weeds growth. This study aimed to evaluate the effect of ethanolic extract of leaves and fruits of Banisteriopsis oxyclada on seedling growth of wild poinsettia and barnyardgrass. Crude ethanolic extract was prepared at a proportion of $100 \mathrm{~g}$ of dry plant matter for $500 \mathrm{~mL}$ of ethanol. Through this, the extracts were solubilized in buffer solution and dimethyl sulfoxide (DMSO), at the concentrations 10.0; 7.5; 5.0; and 2.5 mg/mL. The growth of roots, shoots, and seedling root metaxylem cells were evaluated. Ethanolic extracts of leaves and fruits of $B$. 
oxyclada inhibited root growth of barnyardgrass and wild poinsettia seedlings, with a concentration-dependent effect. Decreased shoot growth was observed only in wild poinsettia seedlings. Decreased root growth in wild poinsettia seedlings may be related to decreased elongation in metaxylem cells. Banisteriopsis oxyclada shows phytotoxic properties and it may be regarded as an alternative to control the weeds under study, having natural products as a basis.

Key words: Allelopathy; Echinochloa crus-galli; Euphorbia heterophylla; Inhibition

\section{Introdução}

As plantas daninhas causam mais prejuízo à agricultura do que as pragas e doenças e constituem a maior barreira para a produção de alimentos e desenvolvimento econômico de muitas regiões do mundo (FERREIRA et al., 2000). Além dos prejuízos diretos, essas plantas reduzem a eficiência agrícola, aumentam os custos de produção e diminuem a qualidade do produto, reduzindo o seu valor comercial, e ainda dificultam ou até impedem a operação de colheita (VASCONCELOS et al., 2012). Por esse motivo, a descoberta de novos compostos químicos com atividade herbicida é de fundamental importância para a agricultura.

O uso de pesticidas derivados da indústria química para o controle de pragas na agricultura moderna tem sido questionado pela sociedade, em decorrência dos efeitos negativos que ocasionam, conforme alerta de Carneiro et al. (2012). Dentre as estratégias de prospecção de herbicidas naturais ou práticas de manejo alternativo que reduzem a utilização de produtos químicos, destacam-se os estudos fundamentados na alelopatia (BALBINOT-JUNIOR, 2004). Esta se caracteriza pela interação positiva ou negativa de espécies vegetais ou microorganismos sobre o crescimento de sistemas biológicos (PINTO, 2002), a qual é atribuída aos aleloquímicos, isto é, compostos biossintetizados via metabolismo secundário e liberados (volatilização, exsudação radicular, lixiviação ou decomposição de resíduos) no ambiente, a partir de tecido vivo ou morto de qualquer parte do vegetal (SOUZA FILHO; ALVES, 2002). Estudos de alelopatia têm avaliado a ação de diversos extratos e metabólitos secundários bioativos, extraídos de material vegetal, com resultados promissores para o controle de plantas daninhas (CÂNDIDO et al., 2013; IMATOMI et al., 2013b; GRISI et al., 2015). O controle dessas espécies, mediante a aplicação de aleloquímicos, pode ter uma importância estratégica pela sua atuação seletiva e pelo baixo poder residual (RIZVI et al., 1999). O uso de algumas espécies vegetais com capacidade fitotóxica no manejo de plantas daninhas tem despontado como uma alternativa promissora nos sistemas agroecológicos (ALBUQUERQUE et al., 2011).

Basicamente, os aleloquímicos podem apresentar mecanismos de ação diretos ou indiretos sobre a planta alvo. Os efeitos indiretos incluem alterações nas propriedades e características nutricionais do solo e, também, nas populações ou atividades de organismos. Já os efeitos diretos, que são mais estudados, incluem alterações no crescimento e no metabolismo vegetal, sendo que compreendem alterações ao nível celular, fotossintético e respiratório, bem como modificações no funcionamento de membranas, na absorção de nutrientes e nas relações hídricas, entre outras (REIGOSA et al., 1999; SOUZA, et al., 2005; DE CONTI; FRANCO, 2011). Diversos métodos podem ser utilizados na identificação de substâncias alelopáticas e, muitos destes em laboratório, são baseados na obtenção de extratos de plantas, em que podem ser empregados solventes orgânicos, como o etanol, metanol ou acetato de etila, e a água (VIDAL, 2010). O resultado de laboratório é o primeiro passo para a identificação do comportamento de plantas associado com aleloquímicos (RIZZARDI et al., 2008). Esses biotestes são mais indicados devido à complexidade das inter-relações planta e ambiente que podem interferir na atividade dos metabólitos secundários. Embora não revelem os compostos ou fenômenos envolvidos, podem detectar a interferência no crescimento e no desenvolvimento das espécies testadas, contribuindo com a indicação de possíveis fontes de novos compostos com bioatividade potencial (MAIRESSE et al., 2007; LOUSADA et al., 2012). 
O gênero Banisteriopsis, pertencente à família Malpighiaceae, apresenta distribuição pantropical, com grande diversidade de espécies encontradas no continente sul-americano (JUDD et al., 1999; SOUTO; OLIVEIRA, 2012), entretanto, a maior diversidade de espécies encontra-se nos cerrados do planalto central brasileiro (GATES, 1982). O gênero Banisteriopsis tem sido relatado na literatura, principalmente, pelo seu potencial medicinal, com atividades antimicrobiana, anti-inflamatória e moduladora do sistema nervoso central (FRIAS et al., 2012; PÁDUA et al., 2013). Essas e outras atividades biológicas foram descritas devido à presença de metabólitos secundários tais como flavonoides, taninos e alcaloides, isolados de diferentes espécies pertencentes ao gênero (FRIAS et al., 2012).

Banisteriopsis oxyclada (A. Juss.) B. Gates é uma liana nativa, denominada popularmente de cipó-folhade-prata ou cipó-prata, está presente em diferentes formações vegetais brasileiras, sendo bastante comum em vegetação do Cerrado (ISHARA; MAIMONIRODELLA, 2012). A floração ocorre de novembro a junho e a frutificação de março a julho (GATES, 1982). Não foram encontrados trabalhos que tratam de investigações sobre o potencial de B. oxyclada e de seus metabólitos secundários para atuarem como potenciais pesticidas naturais, especialmente no que concerne a sua ação herbicida. Neste contexto, os objetivos do estudo foram (1) avaliar o potencial fitotóxico do extrato etanólico de folhas e frutos de B. oxyclada sobre crescimento de plântulas das espécies daninhas capimarroz (Echinochloa crus-galli (L.) Beauv.) e amendoimbravo (Euphorbia heterophylla L.); e (2) analisar o efeito dos extratos no crescimento das células do metaxilema em raízes de plântulas de amendoim-bravo.

\section{Material e Métodos}

\section{Coleta do material vegetal e preparo dos extratos}

Folhas e frutos de B. oxyclada foram coletados de indivíduos ocorrentes na área de reserva de cerrado "sensu stricto" pertencente à Universidade Federal de São Carlos (UFSCar), estado de São Paulo (21 $58^{\circ}$ ' a $22^{\circ} 00^{\prime}$ S e $47^{\circ} 51^{\prime}$ a $\left.47^{\circ} 52^{\prime} \mathrm{W}\right)$, em julho de 2012. Após a coleta, o material vegetal de cada órgão foi seco em estufa de circulação, por 72 h, triturado em moinho industrial, pesado e embalado a vácuo em sacos plásticos e armazenado em temperatura ambiente, até a realização dos experimentos.

Os extratos etanólicos de cada órgão foram preparados utilizando-se $100 \mathrm{~g}$ de material vegetal (pó) em $500 \mathrm{~mL}$ de etanol. Os extratos permaneceram em repouso no escuro, durante $24 \mathrm{~h}$ a $4^{\circ} \mathrm{C}$ e, em seguida, foram filtrados a vácuo, utilizando-se uma bomba elétrica acoplada a um funil de Buchner forrado internamente com papel-filtro e evaporados até a secagem.

Para o preparo das soluções a serem testadas nos bioensaios, os extratos de folhas e frutos foram solubilizados, separadamente, em solução tampão (10 mM de ácido 2-[N-morfolino] etanossulfônico (MES) e $1 \mathrm{M}$ de $\mathrm{NaOH}, \mathrm{pH}=6$ ) e DMSO (dimetilsulfóxido, $5 \mu \mathrm{L}$ $\mathrm{mL}^{-1}$ ) em concentrações de 10,$0 ; 7,5 ; 5,0$ e $2,5 \mathrm{mg} / \mathrm{mL}$. Adicionalmente, foi realizado um controle com solução tampão e DMSO (5 $\mu \mathrm{L} / \mathrm{mL}$ ) (MACÍAS et al., 2010).

\section{Bioensaios de crescimento de plântulas}

Para padronizar a escolha das sementes prégerminadas a serem utilizadas no bioensaio de crescimento de plântulas, cerca de 50 sementes de cada uma das plantas alvo foram colocadas para germinar previamente em placas de Petri de $15 \mathrm{~mm}$ de diâmetro, forradas ao fundo com papel para germinação e regadas com água destilada (ANESE et al., 2015a). Em seguida, as placas de Petri foram tampadas, envolvidas com plástico filme e mantidas na câmara de germinação a $25^{\circ} \mathrm{C}$, sob fotoperíodo de $12 \mathrm{~h}$ luz/12 h escuro.

Posteriormente, sementes pré-germinadas, com emissão da raiz primária com cerca de $3 \mathrm{~mm}$ de comprimento, foram transplantadas para caixas plásticas transparentes $(8 \times 12 \times 3 \mathrm{~cm})$. As caixas foram forradas com duas camadas de papel filtro e umedecidas com 5 $\mathrm{mL}$ das diferentes concentrações dos extratos etanólicos obtidos das folhas e frutos de $B$. oxyclada e água destilada (controle), totalizando 10 sementes pré-germinadas por caixa, com quatro repetições para cada tratamento. Em seguida, as caixas foram tampadas e incubadas em 
câmara de germinação a $25^{\circ} \mathrm{C}$, sob fotoperíodo de 12 h luz/12 h escuro. Após sete dias, os comprimentos da parte aérea (do colo ao meristema apical caulinar) e das raízes (do colo ao meristema radicular) foram medidos com auxílio de um paquímetro digital.

\section{Bioensaio com células do metaxilema}

Plântulas de amendoim-bravo cresceram nas soluções dos extratos de folhas e frutos de $B$. oxyclada e no controle, nas mesmas condições adotadas para o bioensaio de crescimento. Decorridos cinco dias da instalação do experimento, as plântulas foram retiradas das caixas e, com auxilio de um estilete, foi removido o segmento da raiz primária, que foi imerso, imediatamente, em álcool 70\%.

A coloração foi realizada de acordo com o método de Fuchs modificado (KRAUS; ARDUIN, 1997). As raízes ficaram imersas em álcool (70\%) durante cinco dias, sendo depois colocadas em solução de soda cáustica $\left(\mathrm{NaOH}\right.$ a $25 \%$ ), em estufa regulada a $60^{\circ} \mathrm{C}$, durante $48 \mathrm{~h}$, período em que foi observada a clarificação do material.

Em seguida, o material clarificado foi colocado em um recipiente contendo safranina $\left(\mathrm{C}_{20} \mathrm{H}_{19} \mathrm{~N}_{4} \mathrm{C}_{1}\right)$ e soda cáustica $(\mathrm{NaOH}$ a $10 \%)$, e transferido para estufa, a $60{ }^{\circ} \mathrm{C}$, por $24 \mathrm{~h}$. Após a coloração, o material foi fixado em lâminas de vidro com xarope Apathy para observação em microscópio óptico (Olympus-BX41), acoplado com câmara fotográfica (Sony CCD-IRIS). Foram utilizadas quatro repetições de raízes primárias crescidas nas diferentes concentrações das soluções dos extratos de folhas e frutos de B. oxyclada, e no controle. De cada raiz foi fotografado $50 \%$ de seu comprimento total, da região central em direção ao colo (GATTI et al., 2010), no aumento de 20 vezes. De cada fotografia foram medidas até 10 células centrais do metaxilema, utilizando-se o programa Image Pro-Plus 5.0.

\section{Análise estatística}

O experimento foi instalado segundo um delineamento experimental inteiramente casualizado, com quatro repetições. Os tratamentos foram arranjados em um esquema fatorial $2 \times 5$ (dois extratos e cinco concentrações). Os dados obtidos foram submetidos aos testes de normalidade (Shapiro-Wilk) e homogeneidade (Levene). Quando essas duas pressuposições foram atendidas, foi aplicada a análise de variância (ANOVA), seguida pelo teste de Scott-Knott a 0,05 de probabilidade. Para os bioensaios de crescimento de plântulas, quando o resultado da ANOVA foi significativo, procedeu-se à regressão quadrática. $\mathrm{O}$ ajuste do modelo foi testado a 0,05 de significância e avaliado pelo seu coeficiente de determinação $\left(\mathrm{R}^{2}\right)$. No entanto, nos casos em que não foi possível o ajuste dos modelos $\left(\mathrm{R}^{2}\right.$ inferior a $0,70 \%$ ) ou quando os resultados não apresentaram diferenças significativas entre os tratamentos, os valores foram representados no gráfico com os desvios-padrão.

\section{Resultados}

Os extratos etanólicos obtidos de frutos e folhas de B. oxyclada apresentaram efeito fitotóxico sobre o crescimento da raiz e da parte aérea de amendoimbravo e sobre o crescimento radicular de capim-arroz. As plântulas de amendoim-bravo que cresceram na presença do extrato do fruto apresentaram decréscimos significativos nos valores de crescimento radicular e parte aérea em função do incremento das concentrações. Sob o efeito do extrato das folhas, também foi observada redução no crescimento da raiz e da parte aérea de acordo com o aumento das concentrações dos extratos (Figura 1).

O crescimento radicular das plântulas de capimarroz também foi sensível aos efeitos dos extratos de frutos e folhas de $B$. oxyclada, com significativa redução após o aumento da concentração. No entanto, não foi observado efeito significativo dos extratos de frutos e folhas de B. oxyclada sobre o crescimento da parte aérea de capim-arroz (Figura 2).

No presente estudo, evidenciou-se que as raízes de ambas as espécies alvos foram sensíveis aos extratos de folhas e frutos de B. oxyclada. A especificidade de extratos e aleloquímicos oriundos de plantas para inibir com maior eficiência o sistema radicular de espécies alvo, particularmente plantas daninhas, já foi evidenciada em estudos anteriores sobre fitotoxicidade (GRISI et al., 2012; TEERARAK et al., 2012; ANESE et al., 2015b). As raízes geralmente são mais sensíveis às substâncias 
FIGURA 1: Comprimento radicular e da parte aérea de plântulas de amendoim-bravo submetidas aos efeitos dos extratos etanólicos de frutos ( ) e folhas ( $\square)$ de B. oxyclada.
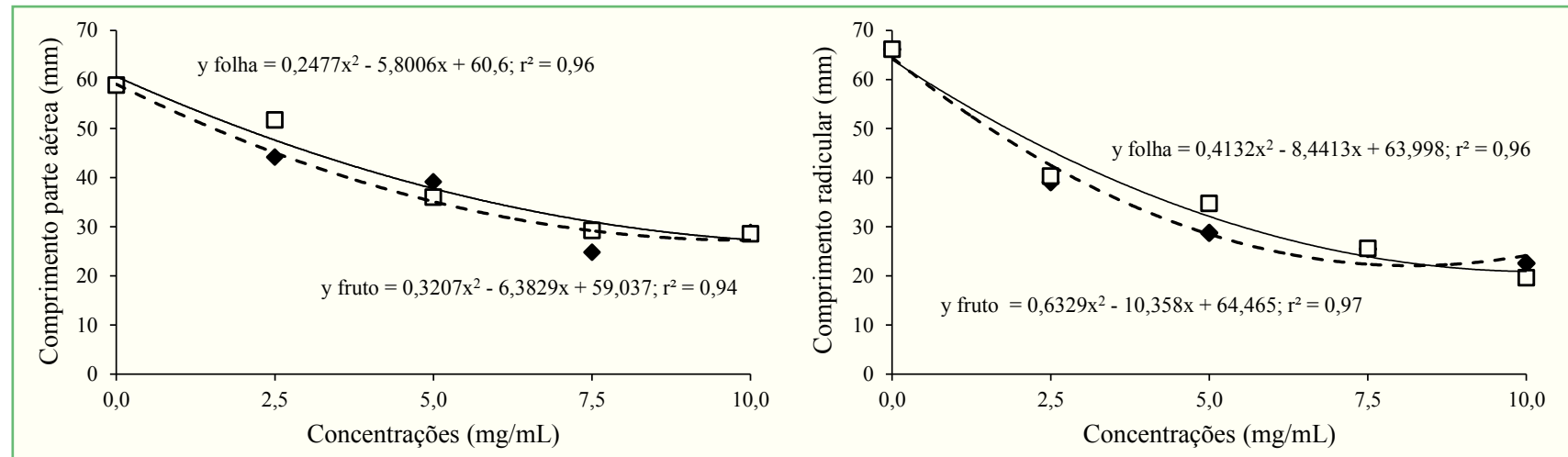

FIGURA 2: Comprimento radicular e da parte área de plântulas de capim-arroz submetidas aos efeitos dos extratos etanólicos de frutos (४) e folhas ( $\square$ ) de B. oxyclada.

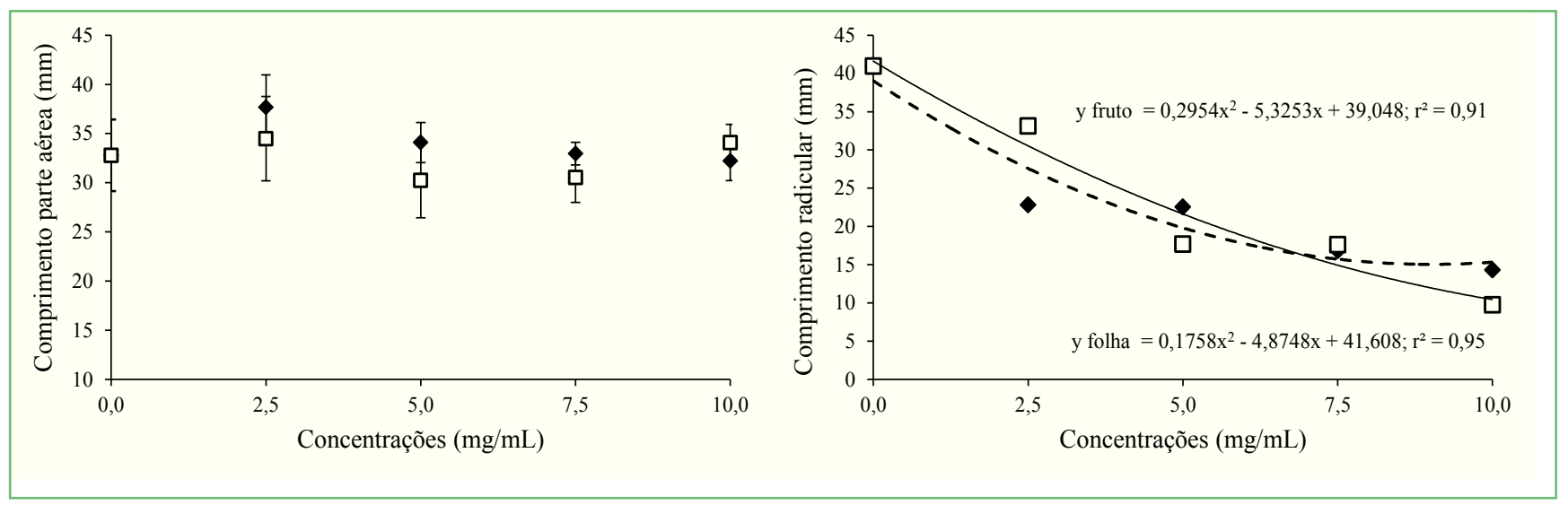

presentes nos extratos quando comparadas com as demais estruturas das plântulas, pois estão em contato direto e prolongado com o extrato (aleloquímicos) em relação às demais estruturas das plântulas e/ou a um reflexo da fisiologia distinta entre as estruturas (AQUILA, 2000; DE CONTI; FRANCO, 2011). Modificações no crescimento e desenvolvimento radicular de plântulas em resposta a compostos fitotóxicos podem ser explicadas por alterações na estrutura e ciclo celular, desintegração da coifa, aumento de diâmetro do cilindro vascular, antecipação da lignificação do metaxilema e da parede celular (SANTOS et al., 2008; SOLTYS et al., 2011).

Contudo, em relação ao crescimento da parte aérea, o efeito dos extratos de folhas e frutos foi significativo apenas para as plântulas de amendoim-bravo. Diferenças de sensibilidade entre as espécies alvo são comuns em estudos de alelopatia (IMATOMI et al., 2013a; WALSH et al., 2014; ANESE et al., 2015b) e podem ser explicados pelo fato de os mecanismos de absorção, translocação e ação das fitotoxinas variarem entre espécies (MAGIERO et al., 2009). De acordo com Imatomi et al. (2013a), a resposta espécie-dependente aos aleloquímicos mostra que eles são fundamentais não só em ambientes naturais, onde influenciam a composição florística, mas também na agricultura, onde podem ser usados como herbicidas seletivos.

O estudo anatômico de raízes de plântulas de amendoim-bravo permitiu a visualização dos efeitos fitotóxicos dos extratos etanólicos de folhas e frutos de $B$. oxyclada em nível celular. As células do metaxilema de 
raízes de plântulas de amendoim-bravo que cresceram na presença do controle $(0,0 \mathrm{mg} / \mathrm{mL})$ apresentaram tamanho médio de $260 \mu \mathrm{m}$. As plântulas crescidas na presença dos extratos de ambos os órgãos, exceto na concentração de $2,5 \mathrm{mg} / \mathrm{mL}$, apresentaram o comprimento das células do metaxilema menores do que o grupo controle. Embora não tenha sido observada diferença significativa entre as concentrações de 5,0; 7,5 e $10 \mathrm{mg} / \mathrm{mL}$, os menores valores visualizados foram de 87,97 e 77,98 $\mu \mathrm{m}$ para os extratos de folhas e frutos na maior concentração testada, respectivamente. Não foram observadas diferenças nos efeitos ocasionados entre os extratos de folhas e frutos, em todas as concentrações avaliadas (Figura 3 ).

A partir dos dados de porcentagem de células distribuídas em classes de tamanho, observou-se que no grupo controle $(0,0 \mathrm{mg} / \mathrm{mL})$ e na concentração de $2,5 \mathrm{mg} / \mathrm{mL}$ dos extratos de ambos os órgãos houve uma distribuição homogênea no tamanho celular, os maiores percentuais, que variam de 25 a $30 \%$ nesses tratamentos, foram encontrados para células com tamanhos entre 195-245 $\mu \mathrm{m}$ (Figura 4). Para o grupo controle não foram registradas células menores que $145 \mu \mathrm{m}$. De forma diferente, as células sobre a influência das demais concentrações avaliadas apresentaram predominância de tamanho menor que $145 \mu \mathrm{m}$. Para a concentração de 10 $\mathrm{mg} / \mathrm{mL}$, em ambos os órgãos, percentuais acima de $70 \%$ foram encontrados para células pertencentes ao tamanho entre 45 e $95 \mu \mathrm{m}$ (Figura 4).

No presente trabalho, o estudo anatômico em raízes de plântulas de amendoim-bravo possibilitou uma melhor visualização dos efeitos dos extratos de folhas e frutos de B. oxyclada em nível celular. Ambos os extratos foram eficientes em reduzir o crescimento das células do metaxilema da espécie alvo, com efeito dependente da concentração avaliada. Os aleloquímicos interferem no processo de divisão celular e alteram os hormônios vegetais, assim, a inibição do alongamento celular pode ser consequência da ação direta dessas substâncias (ALWAKEEL et al., 2007). O crescimento de células do metaxilema de amendoim-bravo foi inibido pela ação de aleloquímicos presentes em extratos etanólicos de folhas de Serjania lethalis (Sapindaceae) (GRISI et al., 2013). Neste mesmo trabalho, os autores relatam que a atividade fitotóxica dos extratos etanólicos foi dependente da concentração testada, sendo que para a maior concentração foi atribuída a maior atividade.

FIGURA 3: Tamanho médio das células do metaxilema $(\mu \mathrm{m})$ de raízes de plântulas de amendoim-bravo sob o efeito de diferentes concentrações do extrato etanólico de folhas e frutos de B. oxyclada e do controle. Letras maiúsculas comparam as concentrações dentro de cada órgão, e minúsculas cada concentração entre os órgãos. Letras iguais não diferem entre si pelo teste de Scott-Knott, a $0,05 \%$ de probabilidade.

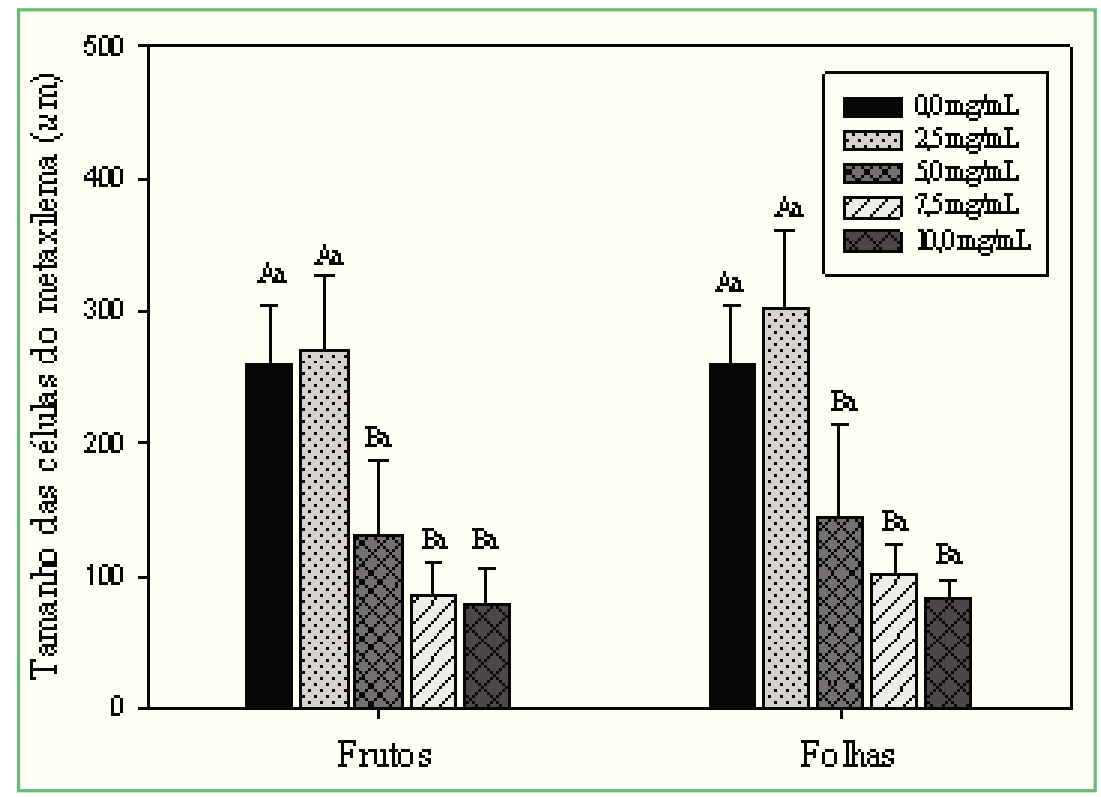


FIGURA 4: Frequências relativas das classes de tamanho $(\mu \mathrm{m})$ das células do metaxilema de raízes de plântulas de amendoim-bravo que cresceram no controle e na presença de diferentes concentrações do extrato etanólico de folhas e frutos de B. oxyclada.

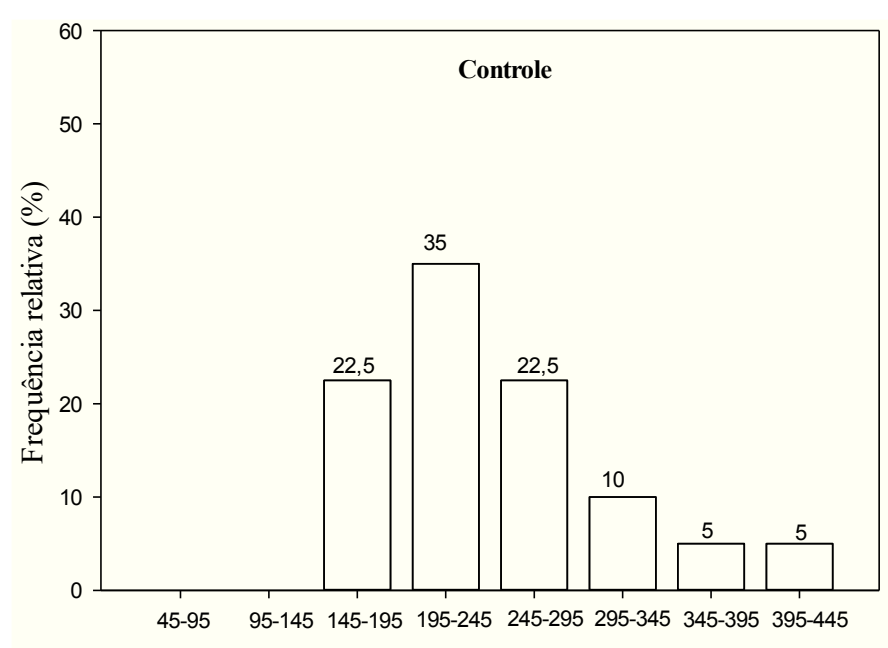

Classes de tamanho
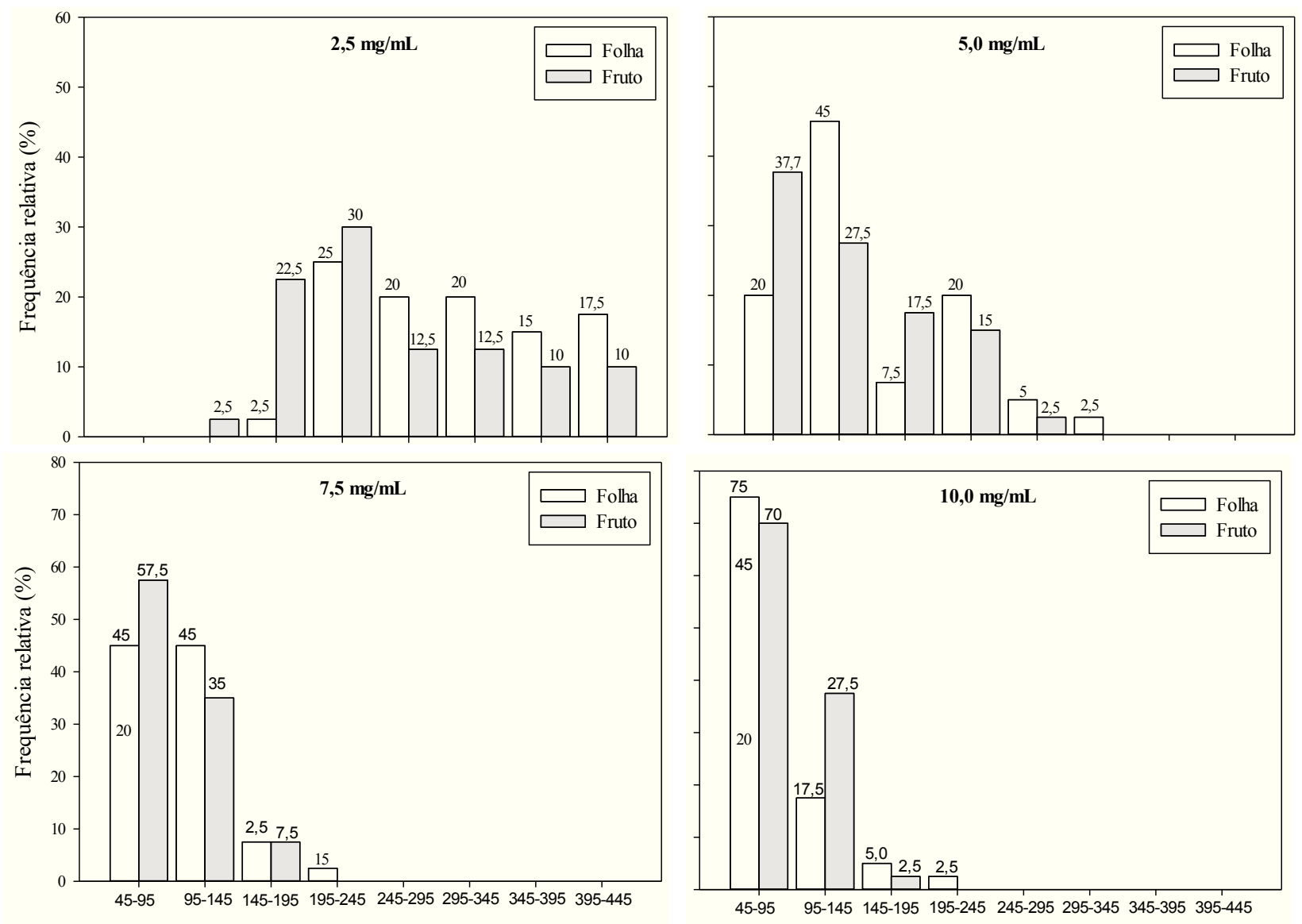

Classes de tamanho

Classes de tamanho 
Metabólitos secundários com potencial fitotóxico são produzidos em diferentes órgãos das plantas, incluindo folhas, caules, cascas, raízes e frutos; contudo, a quantidade de substâncias varia de um órgão para o outro (WESTON; DUKE, 2003; PARVEZ et al., 2004). Estudos recentes demonstraram que os extratos preparados a partir de diferentes órgãos de uma mesma planta com potencial alelopático foram capazes de suprimir a germinação ou crescimento de plantas testes (OLIVEIRA et al., 2012; LINHARES NETO et al., 2014; HABERMANN et al., 2015). Da mesma forma, no presente trabalho, folhas e frutos de $B$. oxyclada apresentaram efeitos fitotóxicos sobre ambas as espécies de plantas daninhas investigadas. Neste sentido, ambos os órgãos da espécie constituem uma opção promissora para posteriores estudos de isolamento e identificação de fitotoxinas naturais com potencial herbicida.

A família Malpighiaceae representa a sétima mais representativa do cerrado (NOVAES et al., 2013), no entanto há poucos relatos sobre o perfil químico e potencial fitotóxico de espécies dessa família. Uma das espécies mais estudadas é a Banisteriopsis caapi, conhecida por apresentar compostos psicoativos, sendo fonte dos alcaloides harmina, tetrahidroharmina (THH) e harmalina (CALLAWAY, 2005). O potencial fitotóxico de harmalina e harmina foi comprovado sobre diásporos e plântulas de Lactuca sativa, Amaranthus sp., Triticum aestivum e Lolium perenne, com destaque para a harmalina sobre o alongamento de raiz das eudicotiledôneas, em concentração de $5 \mu \mathrm{g} \mathrm{mL}^{-1}$ (SHAO et al., 2013). A atividade em baixas concentrações é uma das vantagens do uso de herbicida natural em relação ao sintético, a qual foi evidenciada pelos resultados de Shao et al. (2013) com o uso de harmalina. O extrato etanólico dos frutos de Byrsonima intermedia, outra espécie da família Malpighiaceae encontrada no Cerrado, apresentou efeitos fitotóxicos sobre as espécies alvo tomate e cebola, sendo a atividade atribuída ao elevado conteúdo de compostos fenólicos (PERES et al., 2013).

Pelo resultado obtido no presente estudo, pode-se supor que B. oxyclada possui potencial fitotóxico para controlar plantas daninhas. Até o presente momento, não existem relatos de estudos sobre a presença de metabólitos secundários e potencial fitotóxico na espécie investigada. Desta forma, os resultados obtidos no presente trabalho indicam que $B$. oxyclada se constitui um alvo interessante para o desenvolvimento de estudos fitoquímicos, visando selecionar compostos que possam ser bons candidatos para o desenvolvimento de futuros herbicidas naturais. A vantagem dos compostos alelopáticos é que geralmente exibem bioatividade em baixas concentrações, são biodegradáveis, raramente contêm átomos halogenados e têm baixa ou nenhuma toxicidade sobre espécies não alvo (OLIVEROSBASTIDAS, 2008; FAROOQ et al., 2011), o que poderá contribuir para o desenvolvimento de uma agricultura mais sustentável, que respeita o meio ambiente e valoriza a biodiversidade.

\section{Referências}

ALBUQUERQUE, M. B.; SANTOS, R. C.; LIMA, L. M.; FILHO, P. A. M.; NOGUEIRA, R. J. M. C.; CÂMARA, C. A. G.; RAMOS, A. R. Allelopathy, an alternative tool to improve cropping systems. Agronomy for Sustainable Development, Paris, v. 31, n. 2, p. 379-395, 2011.

AL-WAKEEL, S. A. M.; GABR, M. A.; HAMID, A. A.; ABU-ELSOUD, W. M. Allelopathic effects of Acacia nilotica leaf residue on Pisum sativum L. Allelopathy Journal, New York, v. 19, n. 2, p. 411-422, 2007.

ANESE, S.; GRISI, P. U.; JATOBÁ, L. J.; PEREIRA, V. C.; GUALTIERI, S. C. J. Phytotoxic activity of different plant parts of Drimys brasiliensis Miers on germination and seedling development. Bioscience Journal, Uberlândia, v. 31, n. 3, p. $923-$ 933, 2015a.

ANESE, S.; GUALTIERI, S. C. J.; GRISI, P. U.; JATOBA, L. J.; ARDUIN, M. Phytotoxic potential of Drimys brasiliensis Miers for use in weed control. Acta Scientiarum Agronomy, Maringá, v. 37, n. 4, p. 505-516, 2015 b.

AQUILA, M. E. A. Efeito alelopático de Ilex paraguariensis A. St. -Hil. na germinação e crescimento inicial de Lactuca sativa L. Iheringia Série Botânica, Porto Alegre, v. 53, n. 23, p. 51-66, 2000.

BALBINOT-JUNIOR, A. A. Manejo das plantas daninhas pela alelopatia. Agropecuária Catarinense, Florianópolis, v. 17, n. 1, p. 61-64, 2004.

CALLAWAY, J. C. Various alkaloid profiles in decoctions of Banisteriopsis caapi. Journal of Psychoactive Drugs, San Francisco, v. 37, n. 2, p. 151-155, 2005.

CÂNDIDO, A. C. S.; SILVA, C. B.; SIMIONATTO, E.; BIGATON, D.; SCALON, S. P. Q.; PERES, M. T. L. P.. Atividade fitotóxica de Croton doctoris S. Moore. Ciência Rural, Santa Maria, v. 43, n. 4 , p. 645-652, 2013.

CARNEIRO, F. F.; PIGNATI, W.; RIGOTTO, R. M.; AUGUSTO, L. G. S.; RIZOLlO, A. Dossiê ABRASCO - Um alerta sobre os impactos dos agrotóxicos na saúde. 1르 Parte. Rio de Janeiro: ABRASCO, 2012. 98 p. 
DE CONTI, D.; FRANCO, E. T. H. Efeito alelopático de extratos aquosos de Casearia sylvestris Sw. na germinação e no crescimento de Lactuca sativa L. Revista Brasileira de Agrociência, Pelotas, v. 17, n. 2-4, p. 193-203, 2011.

FAROOQ, M.; ZAHID, K. J.; CHEEMA, A.; WAHID, A.; SIDDIQUE, K. H. M. The role of allelopathy in agricultural pest management. Pest Management Science, Malden, v. 67, n. 5, p. 493-506, 2011.

FERREIRA, M. L.; BARBOSA, L. C. A.; DEMUNER, A. J.; SILVA, A. A.; PEREIRA, R. C. Avaliação da atividade herbicida de algumas quinonas. Acta Scientiarum, Maringá, v. 22, n. 4, p. 999-1003, 2000.

FRIAS, U. A.; COSTA, M. C. M.; TAKAHASHI, J. A.; OKI, Y. Banisteriopsis species: a source of bioactive of potential medical application. International Journal of Biotechnology for Wellness Industries, Mississauga, v. 1, n. 3, p. 163-171, 2012.

GATES, B. Banisteriopsis, Diplopterys (Malpighiaceae). Flora Neotropica Monograph, New York, n. 30, p. 1-236, 1982.

GATTI, A. B.; FERREIRA, A. G.; ARDUIN, M.; PEREZ, S. C. J. G. A. Allelopathic effects of aqueous extracts of Aristolochiaesperanzae O.Kuntze on development of Sesamum indicum L. seedlings. Acta Botanica Brasílica, Feira de Santana, v. 24, n. 2, p. 454-461, 2010.

GRISI, P. U.; FORIM, M. R.; COSTA, E. S.; ANESE, S.; FRANCO, M. F.; EBERLIN, M. N.; GUALTIERIS, S. C. J. Phytotoxicity and identification of secondary metabolites of Ssapindus saponaria L. leaf extract. Journal of Plant Growth Regulation, Dordrecht, v. 39, n. 2, p. 339-349, 2015.

GRISI, P. U.; GUALTIERI, S. C. J.; ANESE, S.; PEREIRA, V. C., FORIM, M. R. Efeito do extrato etanólico de Serjania lethalis no controle de plantas daninhas. Planta Daninha, Viçosa, v. 31, n. 2, p. 239-248, 2013.

GRISI, P. U.; RANAL, M. A.; GUALTIERI, S. C. J.; SANTANA, D. G. Allelopathic potential of Sapindussaponaria L. leaves in the control of weeds. Acta Scientiarum Agronomy, Maringá, v. 34, n. 1, p. 1-9, 2012.

HABERMANN, E.; IMATOMI, M.; PEREIRA, V. C.; CEVITHEREZA PONTES, F.; GUALTIERI, S. C. J. Atividade fitotóxica de cascas do caule e folhas de Blepharocalyx salicifolius (Myrtaceae) sobre espécies infestantes. Acta Biológica Colombiana, Bogotá, v. 20, n. 1, p. 153-162, 2015.

IMATOMI, M.; NOVAES, P.; GUALTIERI, S. C. J. Interspecific variation in the allelopathic potential of the family Myrtaceae. Acta Botanica Brasilica, Feira de Santana, v. 27, n. 1, p. 54-61, 2013a.

IMATOMI, M.; NOVAES, P.; MATOS, A. P.; GUALTIERI, S. C. J.; MOLINILLO, J. M. G.; LACRET, R.; VARELA, R. M.; MACÍAS, F. A. Phytotoxic effect of bioactive compounds isolated from Myrcia tomentosa (Myrtaceae) leaves. Biochemical Systematics and Ecology, Maryland Heights, v. 46, p. 29-35, 2013 b.

ISHARA, K. L.; MAIMONI-RODELLA, R. C. S. Richness and similarity of the Cerrado vascular flora in the central west region of São Paulo state, Brazil. Check List, Rio Claro, v. 8, n. 1, p. 32-42, 2012.

JUDD, W. S.; CAMPBELL, C. S.; KELLOG, E. A.; STEVENS, P. F. Plant systematics. A phylogenetic approach. Sunderland: Sinauer Associates, 1999. 464 p.

KRAUS, J. E.; ARDUIN, M. Manual básico de métodos em morfologia vegetal. Seropedica: EDUR, 1997. 198 p.

LINHARES NETO, M. V.; SANTANA, F. S.; MALHIEROS, R. S. P.; MACHADO, L. L.; MAPELI, A. M. Avaliação alelopática de extratos etanólicos de Copaifera sabulicola sobre o desenvolvimento inicial de Lactuca sativa, Lycopersicum esculentum e Zea mays. Biotemas, Florianópolis, v. 27, n. 3, p. 23-32, 2014.

LOUSADA, L. L.; LEMOS, G. C. S.; FREITAS, S. P.; DAHER, R. F.; ESTEVES, B. S. Bioatividade de extratos hidroalcoólicos de Cymbopogon citratus (DC.) Stapf. Sobre picão-preto (Bidens pilosa L.) e alface (Lactuca sativa L.). Revista Brasileira de Plantas Medicinais, Botucatu, v. 14, n. 2, p. 282-286, 2012.

MACÍAS, F. A.; LACRET, R.; VARELA, R. M.; NOGUEIRAS, C.; MOLINILLO, J. M. G. Isolation and phytotoxicity of terpenes from Tectona grandis. Journal of Chemical Ecology, Tampa, v. 36, n. 4, p. 396-404, 2010.

MAGIERO, E. C.; ASSMANN, J. M.; MARCHESE, J. A.; CAPELIN, D.; PALADINI M. V.; TREZZI, M. M. Efeito alelopático de Artemisia annua L. na germinação e desenvolvimento inicial de plântulas de alface (Lactuca sativa L.) e leiteiro (Euphorbia heterophylla L.). Revista Brasileira de Plantas Medicinais, Botucatu, v. 11, n. 3, p. 317-324, 2009.

MAIRESSE, L. A. S.; COSTA, E. C.; FARIAS, J. R.; FIORIN, R. A. Bioatividade de extratos vegetais sobre alface (Lactuca sativa L.). Revista da FZVA, Uruguaiana, v. 14, n. 2, p. 1-12, 2007.

NOVAES, P.; MOLINILLO, J. M. G.; VARELA, R. M.; MACÍAS, F. A. Ecological phytochemistry of Cerrado (Brazilian savanna) plants. Phytochemistry Reviews, New York, v. 12, n. 4, p. 839855, 2013.

OLIVEIRA, A. K.; COElHO, M. F. B.; MAIA, S. S. S.; DIÓGENES, F. E. P. Atividade alelopática de extratos de diferentes orgãos de Caesalpinia ferrea na germinação de alface. Ciência Rural, Santa Maria, v. 42, n. 8, p. 1397-1403, 2012.

OLIVEROS-BASTIDAS, A J. El fenómeno alelopático. El concepto, las estratégias de estúdio y su aplicación em la búsqueda de herbicidas naturales. Química Viva, Buenos Aires, v. 7, n. 1, p. 1-34, 2008.

PÁDUA, M. S.; MENDES-COSTA, M. C.; FERREIRA, J. M. S.; MAGAlHÃES, J. C.; CASTRO, A. H. F. Assessment of antimicrobial activity in vitro of ethanolic extracts of Banisteriopsis anisandra (A. Juss.) B. Gates (Malpighiaceae). Revista Brasileira de Plantas Medicinais, Botucatu, v. 15, n. 3, p. 431-437, 2013.

PARVEZ, S.; PARVEZ, M.; FUJII, Y.; GEMMA, H. Differential allelopathic expression of bark and seed of Tamarindus indica L. Plant Growth Regulation, Kent, v. 42, n. 3, p. 245-252, 2004.

PERES, M. T. L. P.; LOPES, J. R. R.; SILVA, C. B.; CÂNDIDO, A. C. S.; SIMIONATTO, E.; CABRAL, M. R. P.; OLIVEIRA, R. M.; FACCO, J. T.; CARDOSO, C. A. L.; SIMAS, P. H. Phytotoxic and antioxidant activity of seven native fruits of Brazil. Acta Botanica Brasilica, Feira de Santana, v. 27, n. 4, p. 836-846, 2013.

PINTO, A. C. Produtos naturais: atualidade, desafios e perspectivas. Química Nova, São Paulo, v. 25, n. 1, p. 45-61, 2002.

REIGOSA, M. J.; SANCHEZ MOREIRAS, A. M; GONZALEZ, L. Ecophysiological approach in allelopathy. Critical Reviews in Plant Sciences, Apopka, v. 18, n. 5, p. 577-608, 1999.

RIZVI, S. J. H.; TAHIRC, M.; RIZVIAB, V.; KOHLID, R. K.; ANSARIA, A. Allelopatic interactions in agroforestry systems. Critical Reviews in Plant Sciences, Apopka, v. 18, n. 6, p. 773796, 1999. 
RIZZARDI, A.; RIZZARDI, M. A.; LAMB, T. D.; JOHANN, L. B. Potencial alelopático de extratos aquosos de genótipos de canola sobre Bidens pilosa. Planta Daninha, Viçosa, v. 26, n. 4, p. 717724, 2008.

SANTOS, W. D.; FERRARESE, M. L. L.; NAKAMURA, C. C.; MOURÃO, K. S. M.; MANGOLIN, C. A.; FERRARESE-FILHO, O. Soybean (Glycine max) root lignification induced by ferulic acid: the possible mode of action. Journal of Chemical Ecology, Tampa, v. 34, n. 9, p. 1230-1241, 2008.

SHAO, H.; HUANG, X.; ZHANG, Y.; ZHANG, C. Main Alkaloids of Peganum harmala L. and Their Different Effects on Dicot and Monocot Crops. Molecules, Basel, v. 18, n. 3, p. 2623-2634, 2013.

SOLTYS, D.; RUDZIŃSKA-LANGWALD, A.; KUREK, W.; GNIAZDOWSKA, A. SLIWINSKA, E.; BOGATEK, R. Cyanamide mode of action during inhibition of onion (Allium cepa L.) root growth involves disturbances in cell division and cytoskeleton formation. Planta, New York, v. 234, n. 3, p. 609-621, 2011.

SOUTO, L. S.; OLIVEIRA, D. M. T. Pericarp structure in Banisteriopsis C.B.Rob. and Diplopterys A.Juss. (Malpighiaceae): new data supporting generic segregation. Acta Botanica Brasilica, Feira de Santana, v. 26, n. 3, p. 527-536, 2012.

SOUZA, S. A. M.; CATTELAN, L. V.; VARGAS, D. P.; PIANA, C. F. B.; BOBROWSKI V. L.; ROCHA, B. H. G. Efeito alelopático de plantas medicinais nativas do Rio Grande do Sul sobre a germinação de sementes de alface. Ciências Biológicas e da Saúde, Ponta Grossa, v. 11, n. 3, p. 29-38, 2005.
SOUZA FILHO, A. P.; ALVES, S. M. Alelopatia: princípios básicos e aspectos gerais. Belém: Embrapa Amazônica Oriental, 2002. $260 \mathrm{p}$.

TEERARAK, M.; LAOSINWATTANA, C.; CHAROENYING, P.; KATO-NOGUCHI, H. Allelopathic activities of Jasminum officinale f. var. grandiflorum (Linn.) Kob.: inhibition effects on germination, seed imbibition, and $\alpha$-amylase activity induction of Echinochloa crus-galli (L.) Beauv. African Journal of Biotechnology, Cape Town, v. 11, n. 31, p. 7850-7854, 2012.

VASCONCELOS, M. C. C.; SILVA, A. F. A.; LIMA, R. S. Interferência de plantas daninhas sobre plantas cultivadas. Agropecuária Científica no Semiárido, Campina Grande, v. 8, n. 1, p. 1-6, 2012.

VIDAL, R. A. Interação negativa entre plantas: inicialismo, alelopatia e competição. UFRGS. Porto Alegre, 2010. 132 p.

WALSH, D.; SANDERSON, D.; HALL, L. M.; MUGO, S.; HILLS, M. J. Allelopathic effects of camelina (Camelina sativa) and canola (Brassica napus) on wild oat, flax and radish. Allelopathy Journal, New York, v. 33, n. 1, p. 83-96, 2014.

WESTON L. A.; DUKE, S. O. Weed and crop allelopathy. Critical Reviews in Plant Sciences, Apopka, v. 22, n. 3-4, p. 367-389, 2003. 